\title{
Management of surgical wound dehiscence by oxygen-ozone therapy in a FIV-positive cat - a case report
}

\author{
Călin Cosmin Repciuc ${ }^{1}$, Corina Gina Toma ${ }^{2}$, Ciprian Andrei Ober ${ }^{1}$, Liviu Ioan Oana ${ }^{1}$ \\ University of Agricultural Sciences and Veterinary Medicine of Cluj-Napoca, Faculty of Veterinary Medicine, \\ ${ }^{1}$ Department of Surgery, ${ }^{2}$ Department of Pathology, Cluj-Napoca, Romania
}

Received January 13, 2020

Accepted May 26, 2020

\begin{abstract}
Patients infected with the feline immunodeficiency virus (FIV) are frequently victims of postoperative wound dehiscence due to low efficiency of the immune system that predisposes to delayed scaring and epithelization processes. This case report aimed to describe the successful use of medical ozone in the treatment of a dehisced wound in a feline patient that presented this type of FIV-associated complication. Here we present a case of a 12-year-old, mixedbreed, male, FIV-positive cat with purulent arthritis affecting the shoulder, elbow, and the carpal joints with subsequent periostitis and arthrogryposis affecting the right forelimb. After a thorough investigation (clinical examination, X-rays) it was decided that limb amputation would be the proper choice. The surgical wound did not tend to heal, followed by rejection of the suture material, skin necrosis, and wound dehiscence. After 13 days following the surgery with allopathic treatment and no improvement, oxygen-ozone-therapy was started. Clinically, oxygen-ozone therapy showed significant results after the first session: borders of the wound got into the contraction phase, got attached to the underlying tissues, and exudates were significantly diminished. The therapy continued every 2 days showing improved blood perfusion of the affected area and a visible advancement of the contraction phase daily with complete healing in 1.5 months.
\end{abstract}

Ozone therapy, infiltrations, amputation, chronic wound, feline immunodeficiency virus

Tissue regeneration consists of progressive activation of cellular and biochemical mechanisms immediately after lesion occurs (Sen et al. 2002; Sen and Roy 2007).

Feline immunodeficiency virus (FIV) is a lentivirus that affects domestic cats (Pedersen et al. 1989). Naturally, FIV-infected cats develop immunodeficiency manifested in persistent or seriate pathological processes mainly caused by secondary opportunistic pathogenic agents rather than the virus itself. Immunological dysfunction is the starting point of this disease and it was investigated in perfectly healthy domestic felines, free of FIV, which were experimentally infected (Barlough et al. 1991). These experimentally infected felines provided data supporting the theory that FIV induces a $\mathrm{T}$ helper progressive dysfunction that has immunosuppression as a final effect (Barlough et al. 1991). T helper cells (regulatory cells) play a very important role in the maintenance of immune homeostatic status. This process helps to prevent the autoimmune reactions and the reduction of inflammatory reactions induced by germs or other environmental factors (Lourenço and La Cava 2011).

Ozone-therapy has been proposed in the late $20^{\text {th }}$ century to be a very effective therapy capable to influence the red-ox balance and it is considered to be a therapy with good results in multiple acute or chronic diseases (Traina 2008; Maiya 2011; Gopalakrishnan and Parthiban 2012; Kumar et al. 2014). Also, ozone is a potent oxidant which in contact with biological or organic fluids leads to the formation of reactive oxygen molecules. These molecules influence cellular metabolism in a beneficial way for faster tissue regeneration. Ozone also has a surface antibiotic/bacteriostatic effect (Traina 2008).

Address for correspondence:

Călin Cosmin Repciuc

University of Agricultural Sciences and

Veterinary Medicine of Cluj-Napoca

Calea Mănăștur no. 3-5, Cluj-Napoca, Romania

Phone: +40745775821

E-mail: calin_c repciuc@yahoo.com

http://actavet.vfu.cz/ 
Ozone stimulates and regulates the immune system activity augmenting the synthesis activity of certain organic molecules. It's bioenergetic, anti-hypoxic, analgesic and homeostatic properties are also mentioned in the literature (Das 2011).

Ozone-therapy is a successful method used in the treatment of wounds that tend to have difficulties in the healing process such as diabetic ulcers, distal limb wounds in horses, high surface extended lesions that are difficult to be protected by dressings and are exposed to infections, and wounds that do not heal by conventional therapies (Repciuc et al. 2016). Ozone at precise doses acts like a local antiseptic, tissue oxygenating agent, and epithelization promoter by accelerating the release of platelet growth factors (Bocci et al. 1993; Bocci 2005a; Bocci 2005b).

This case report aimed to describe the successful use of medical ozone in the treatment of a dehisced wound in a feline patient that presented this type of FIV-associated complication.

\section{Case history and the therapeutic protocol}

A 12-year-old, mixed-breed, male outdoor cat was presented to a first opinion veterinary practice with generalized amyotrophy of the right anterior limb, elbow, and carpal joint arthrogryposis. The limb also had multiple periarticular and intraarticular purulent collections on the elbow and shoulder. Physical examination revealed a poor body condition, cachexia, pale mucous membranes, and dehydration (4\%). It was followed by serum biochemistry and haematological exams. Due to a lack of history and the fact that the cat was kept outdoor, a chromatographic immunoassay qualitative test for feline immunodeficiency virus and feline leukaemia virus (VetExpert ${ }^{\mathbb{B}}$ rapid test $^{2}$ FIV Ab/FeLV Ag, Poland) was performed. The therapy consisted in local antiseptic lavages with chlorhexidine, drainage of the abscesses, articular and pericapsular saline lavages followed by a supportive local antibiotic (tetracycline hydrochloride, neomycin sulphate, prednisolone acetate, chymotrypsin, trypsin and papain, Tenazym ${ }^{\circledR}$, Veyx-Pharma $\mathrm{GmbH}$, Germany), systemic antibiotic therapy (amoxicillin and clavulanic acid $8.75 \mathrm{mg} / \mathrm{kg}$ s.c., Synulox $^{\circledR}$ RTU Zoetis, UK) for 14 days and anti-inflammatory treatment (robenacoxib $2 \mathrm{mg} / \mathrm{kg}$ s.c, Onsior ${ }^{\circledR}$, Novartis, Switzerland) for 5 days. The haematological exam showed a significant elevation of the white blood cells (WBC) $17.4 \times 10^{3} / \mu \mathrm{l}\left(5-11 \times 10^{3} / \mu \mathrm{l}\right)$ and moderate anaemia, red blood cells $(\mathrm{RBC}) 4.12 \times 10^{3} / \mu \mathrm{l}\left(5-10 \times 10^{3} / \mu \mathrm{l}\right)$, haemoglobin (HGB) $7.4 \mathrm{~g} / \mathrm{dl}(8-17 \mathrm{~g} / \mathrm{dl})$, and haematocrit (HCT) $23.3 \%(27-47 \%)$. The results were correlated with the physical condition of the cat and the multiple, localized infections. The cat was diagnosed as FIV positive by rapid test, but in order to have a definitive diagnosis, a blood sample was tested for FIV antibodies by the ELISA method in a specialized laboratory and the result was also positive.

After a standard radiological examination, forelimb amputation was recommended because of multiple periosteal reactions, arthrosis, exaggerated tendon retraction, and osseous degenerative aspects in the affected joints (Plate VII, Fig. 1). After 30 days of treatment and recovery the infectious processes disappeared, the general status of the animal improved substantially (anaemia persisted), the drainage fistulas healed, and the amputation was performed. Scapulectomy was performed and a V-shaped flap plastia was performed to cover the defect. Post operation therapy consisted of antibiotics, cephalexin $15 \mathrm{mg} / \mathrm{kg}$, p.o. (Tsefalen ${ }^{\circledR} \mathrm{ICF}$, Italy) and procaine benzylpenicillin/dihydrostreptomycin $20 \mathrm{mg} / \mathrm{kg}$, i.m (Penstrep - Ject ${ }^{\mathbb{R}}$, Dopharma, Romania) for 7 days without tendency of healing.

The evolution of the wound was unsatisfactory and the dehiscence, rejection of the suture material, and superficial necrotic processes began 4 days after the surgery. After 6 days, the wound was completely opened (Plate VII, Fig. 2). Subcutaneous purulent collections were present and the patient showed apathy, anorexia, and fever $\left(40^{\circ} \mathrm{C}\right)$. The initial therapy 
was continued for additional 7 days, adding a local ointment composed of tetracycline hydrochloride, neomycin sulphate, prednisolone acetate, chymotrypsin, trypsin and papain (Tenazym ${ }^{\circledR}$, Veyx-Pharma GmbH, Germany) followed by another clinical evaluation. The fever persisted while there was no improvement in the healing of the dehisced wound, and its area was increasing. After 14 days of allopathic treatment the decision to perform ozone therapy by perilesional and intralesional infiltrations was made. The technique was adapted to the protocol described by the Madrid Declaration on Ozone Therapy (Schwartz-Tapia et al. 2015). A thick absorbent dressing was performed after each therapy session. The dressing consisted of a first layer of sterile absorbent pad (Zetuvit $\mathrm{E}^{\circledR}$ Hartmann, USA), an orthopedic cotton cast padding, and a last cohesive bandage layer (Vet Flex ${ }^{\circledR}$ Henry Schein, USA). The first layer of absorbent pad had non-adherent surfaces in order to prevent damage of the superficial granulation tissue.

For the ozone treatment we used the Medozon Compact $^{\circledR}$ medical ozone generator (Hermann Aparateau GmbH, Germany), a 51 oxygen bottle, 5-10 ml syringes, 25-35 G needles, and materials needed for the protective dressing. The concentration of the oxygenozone mixture used was $15 \mu \mathrm{g} / \mathrm{ml}$ and the volume administrated was $1.0-1.5 \mathrm{ml}$ of gas subcutaneously, perilesional infiltrated at an average $2-3 \mathrm{~cm}$ distance between points and $2 \mathrm{~cm}$ distance from the border of the wound. We also injected the gas in the exposed necrotic pectoral and intercostal muscles at the same distances between inoculations. The total gas quantity inoculated during a session of treatment did not exceed $10 \mathrm{ml}$ and it was reduced proportionally to the advancement of the contraction phase and to the decreasing area of the wound. The treatment sessions took place once every $48 \mathrm{~h}$ until complete epithelization. Before each treatment the wound was cleaned with sterile gauze pads and warm saline. The saline was flushed with a 21 gauge needle attached to a $20 \mathrm{ml}$ syringe. No local antiseptics were used during the ozone treatment.

\section{Results and Discussion}

Previous studies show that feline immunodeficiency virus infection could explain the dehiscence and late healing of feline patients (Pedersen et al. 1989).

The relationship between inflammation and wound healing is kept under control by inflammatory mediators. The mediators are soluble factors released by platelets and white blood cells immediately after the damage of the intact skin occurred and by resident cells of the wounded area later in the healing process. Inflammation is initiated and controlled by multiple soluble factors. The most extensively described mediators involved in wound healing processes are cytokines and growth factors (Henry and Garner 2003).

During the debridement phase, migration of leukocytes leads to the removal of cellular debris and necrotic tissue and the phagocytosis of bacteria. If the animal's immune system is very weak, there will be a lack of migrating leukocytes at the site of the wound, so the isolation of bacteria and removal of cellular debris will be inefficient.

The animal's severe anemia was responsible for the degeneration of superficial tissues and the slow healing process of the wound as well as the lack of growth factors at this level.

For example, TGF- $\beta 1$ has multiple roles in the development of blood vessels that could encompass the formation of solid tissue (Pepper et al. 1990) or regulation of basement membrane synthesis during vessel migration into the granulation tissue (Neubauer et al. 1999). These processes are slowed down by the extremely weakened immune system and its anaemic effect in patients with FIV.

In our case we have also associated the complications that followed surgery to this particular condition (FIV) of our patient. Additionally, the age of the cat (12 years) may have contributed to the severity of the post-surgical complications such as infection, dehiscence, and rejection of the suture material. However, oxygen-ozone therapy showed 
quick improvement (after the first session) of the dehiscent wound whereas several attempts of classic therapy had no effect and the general condition of the cat worsened.

Interestingly, after the first ozone-therapy session the borders of the wound started to contract, becoming attached to the underlying tissues, and exudates were significantly diminished. Macroscopically, the granulation tissue and the skin vascularization improved considerably (Plate VIII, Fig. 3), these processes being shown by the colour of the tissues and the blood drops expressing after the needle used for infiltrating the area was retracted. After the first 3 sessions the general status of the animal improved and the wound had no more abnormal exudative discharge.

Complete healing of the wound occurred after 22 sessions of ozone therapy (Table 1) that lasted for 1.5 months.

Table 1. Evolution of wound reduction.

\begin{tabular}{lcc}
\hline Session no. & Epithelised surface $\left(\mathrm{cm}^{2}\right)$ & Wound surface $\left(\mathrm{cm}^{2}\right)$ \\
\hline 1 (day 0) & 0 & 40.15 \\
2 (day 2) & 18.2 & 21.95 \\
4 (day 6) & 14.34 & 7.61 \\
$15($ day 28$)$ & 2.55 & 5.06 \\
$18($ day 34) & 2.85 & 2.21 \\
$20($ day 38) & 1.09 & 1.12 \\
$0($ day 44$)$ & 1.12 & 0 \\
\hline
\end{tabular}

A higher healing percentage was observed in the first 6 days $\left(9.1 \mathrm{~cm}^{2} /\right.$ day in the first 2 days and $3.58 \mathrm{~cm}^{2} /$ day between days 2-6) with a total reduction of the wound surface of $81.04 \%$ and a $35.71 \%$ reduction compared to day 2. The following 22 days registered a lower surface reduction rate $\left(0.11 \mathrm{~cm}^{2} /\right.$ day between days
duction compared to day 0 and 6-28) compared to days $0-6$, with an $87.39 \%$ surface reduction compared to day 0 and a $6.35 \%$ reduction compared to day 6 .

A study comparing healing differences between cutaneous wounds in healthy dogs and cats found wound reductions of $18.3 \%$ on day $7,59 \%$ on day 14 , and $83.9 \%$ on day 21 (Bohling et al. 2004). Wounds were protected by a dressing composed of a first layer of non-adherent pad (Telfas ${ }^{\circledR}$ adhesive pad, Tyco HealthCare Kendall, Mansfield, MA, USA), open weave cotton roll gauze (Sof-Band ${ }^{\circledR}$ bulky bandage, Johnson \& Johnson Medical, Ethicon Inc., Arlington, TX, USA), and the last layer consisted of a white adhesive tape $\left(Z_{0 n a s}^{\circledR}\right.$, Johnson \& Johnson, USA). No other systemic or local antimicrobial treatments were used (Bohling et al. 2004).

Comparing our results to Bohling's research, we can assess that ozone had a speeding up effect on the total wound reduction percentage in the first 6 days (18.3\% in Bohling et al.'s study vs. $81.4 \%$ in our case). The wound reduction at $21 / 28$ days is similar in both studies $(83.9 \%$ vs. $87.39 \%)$. In the following period, the wound contraction almost ended and was replaced by the epithelization process, which lowered the total reduction speed of the wound.

In another study full-thickness skin wound healing was evaluated in cats (Mitsui et al. 2009). The experimentally induced $4 \mathrm{~cm}^{2}$ wounds were treated for 40 days with ampicillin and the total registered surface reduction was between $90.2 \%$ and $92.5 \%$. In our case the initial $40.15 \mathrm{~cm}^{2}$ wound had a $97.21 \%$ reduction 38 days after the beginning of ozone treatment and healed completely in 44 days.

Topical ozone therapy has been intensely studied and cited in similar human medicine clinical conditions (Martinez-Sanchez et al. 2005; Garcia et al. 2010; Borrelli et al. 2015), like diabetic ulcers which present similarities with our feline patient's wound condition (Borrelli et al. 2015). The effect of ozone over tissues is forced oxygenation and accelerated release of platelet-derived growth factors (Valacchi and Bocci 1999). Kim et al. (2009) performed a study to evaluate the therapeutic effects of ozonated oil in the healing process of induced wounds in swine. The ozone-treated group showed a higher wound dimension reduction rate than the control group. The biopsy samples were 
histologically evaluated and an increase of collagen fibres was observed in the ozonetreated group. Immunohistochemically, an accelerated expression of platelet-derived growth factor (PDGF), transforming growth factor-beta (TGF- $\beta$ ), and vascular endothelial growth factor was observed (Kim et al. 2009). In a study realized to evaluate the effects of ozonized platelet-rich plasma on wound healing increase of interleukin 8 (IL-8), PDGF and TGF- $\beta$ concentrations were observed. IL- 8 is the interleukin responsible for the bloodtissue leukocyte barrier passing mechanism for the phagocytic processes to be possible in wounds or ulcers. This could be a solid argument to justify accelerated tissue regeneration in chronic, atonic wound patients (Valacchi and Bocci 1999).

Ozone reacts with the external layer of bacteria damaging its structural integrity by oxidizing lipoproteins and phospholipids. In fungi it inhibits their divisional process in some certain development phases. In terms of its anti-viral properties, ozone damages the viral capsid and stops the viral division by peroxidation processes (Rilling and Veribahn 1987).

The bactericidal mechanism of ozone consists of the reaction of this gas with the polyunsaturated fatty acids of the phospholipidic layer of the cellular membrane. This way some hydrophilic peroxides are obtained. Affected cells produce high quantities of hydrogen peroxide as a defensive mechanism and are not able to face the effects of other peroxides. As a consequence the bacterial cellular membrane will suffer the process of ozonolysis (Rodriguez et al. 2009). Unfortunately, in our case bacteriological, histological, and immunohistochemical evaluation was not performed since the owner did not agree.

The results of this case report suggest that ozone improves the local peripheral vascularization, accelerates granulation tissue expression, and quickens the contraction phase of chronic wound healing. To the authors' knowledge, there are no published case reports of FIV infected felines with chronic wounds treated by perilesional subcutaneous, intralesional, and intramuscular ozone-therapy. The protocol used for this individual case was adapted from human medicine. Ozone concentration injected was higher than recommended (Schwartz-Tapia et al. 2015) for human use. The purpose of this adjustment was to bring more oxygen to the local hypoxic tissues and to stimulate the local response by a slight irritating effect.

From this standpoint, oxygen-ozone therapy should be considered as an alternative treatment of choice in veterinary medicine, in patients with chronic non-healing wounds. Perilesional and intralesional ozone infiltration methods could be used in the treatment of chronic and poor vascularized wounds in FIV positive feline patients. Moreover, oxygenozone therapy in veterinary medicine has been used more extensively in experimental studies performed on laboratory animals (Valachi et al. 2011; Uysal et al. 2012) and there are few data on case studies in cats and dogs (de F Chonillo and Manzo 2019). Ozone therapy in dogs previously showed good results in purulent bite wounds (Gayon-Amaro and Flores-Colin 2019). This research adds new insights into the usefulness of this procedure in the chronic wound healing process, associated with a chronic immunosuppressive disease. Good effects on the contraction phase of the wound treated with ozone could be observed together with an improvement of the perilesional peripheral blood flow. However, to confirm the positive results obtained in our case report, further clinical trial studies and investigations should be performed to elaborate on the effect of ozone in over-complicated chronic wounds in feline patients associated with a FIV infection.

\section{References}

Barlough JE, Ackley CD, George JW, Levy N, Acevedo R, Moore PF, Rideout BA, Cooper MD, Pedersen NC 1991: Acquired immune dysfunction in cats with experimentally induced feline immunodeficiency virus infection: comparison of short-term and long-term infections. J Acquired Immune Defic Syndr 4: 219-227

Bocci V 2005a: General mechanism of action of ozone therapy and mechanism in pain treatment. Rev Soc Esp Dolor 12: 24-36 
Bocci V 2005b: Ozone A New Medical Drug. Springer, Dordrecht, 295 p.

Bocci V, Luzzi E, Coradeschi F, Paulesu L, Di Stefano A 1993: Studies on the biological effects of ozone: 3. An attempt to define conditions for optimal induction of cytokines. Lymphokine Cytokine Res 12: 121-126

Bohling MW, Henderson RA, Swaim SF, Kincaid SA, Wright JC 2004: Cutaneous wound healing in the cat: A macroscopic description and comparison with cutaneous wound healing in the dog. Vet Surg 33: 579-587

Borrelli E, De Monte A, Bocci V 2015: Oxygen ozone therapy in the integrated treatment of chronic ulcer: a case series report. Int J Recent Sci Res 6: 4132-4136

Das S 2011: Application of ozone therapy in dentistry. Indian J Dent Adv 3: 538-542

de F Chonillo F, Manzo CG 2019: Ozone in the healing process of surgical wounds in dogs and cats. Journal of Asia Pacific Studies 5: 566-586

Garcia CA, Eurides D, Prado BR, Neves Rodrigues MM, Nara Neves SM, Queiroz Rinaldi FC 2010: Skin healing in one equine by therapy with ozone. Rev CENIC, Cienc Biol 41: 1-6

Gayon-Amaro SG, Flores-Colin E 2019: Ozonetherapy for wound management in dogs. Journal of Ozone Therapy $3: 21-22$

Gopalakrishnan S, Parthiban S 2012: Ozone - a new revolution in dentistry. J Bio Innov 1: 58-69

Henry G, Garner WL 2003: Inflammatory mediators in wound healing. Surg Clin North Am 83: 483-507

Kim HS, Noh SU, Han YW, Kim KM, Kang H, Kim HO, Park YM 2009: Therapeutic effects of topical application of ozone on acute cutaneous wound healing. J Korean Med Sci 24: 368-374

Kumar A, Bhagawati S, Tyagi P, Kumar P 2014: Current interpretations and scientific rationale of ozone usage in dentistry: A systematic review of literature. Eur J Gen Dent 3: 175-180

Lourenço EV, La Cava A 2011 : Natural regulatory T cells in autoimmunity. Autoimmunity 44: 33-42

Maiya A 2011: Applications of ozone in dentistry. Int J Clin Dent Sci 2: 23-27

Martinez-Sanchez G, Al-Dalain SM, Menendez S, Re L, Giuliani A, Candelario-Jalil E, Alvarez H, FernandezMontequin JI, Leon OS 2005: Therapeutic efficacy of ozone in patients with diabetic foot. Eur J Pharmacol 523: $151-161$

Mitsui A, Mathews KG, Linder KE, Kruse MA, Roe SC 2009: Effects of fascial abrasion, fasciotomy, and fascial excision on cutaneous wound healing in cats. Am J Vet Res 70: 532-538

Neubauer K, Kruger M, Quondamatteo F, Knittel T, Saile B, Ramadori G 1999: Transforming growth factor-beta1 stimulates the synthesis of basement membrane proteins laminin, collagen type IV and entactin in rat liver sinusoidal endothelial cells. J Hepatol 31: 692-702

Pedersen NC, Yamamoto JK, Ishida T, Hansen H 1989: Feline immunodeficiency virus infection. Vet Immunol Immunopathol 21: 111-129

Pepper MS, Belin D, Montesano R, Orci L, Vassalli JD 1990: Transforming growth factor-beta 1 modulates basic fibroblast growth factor-induced proteolytic and angiogenic properties of endothelial cells in vitro. J Cell Biol 111: 743-755

Repciuc CC, Crecan CM, Oana LI 2016: Ozone therapy in veterinary medicine. Rev Rom Med Vet 26: 49-53

Rilling S, Veribahn R 1987: The Use of Ozone in Medicine. Haug, NewYork

Rodriguez ZZ, Guanche A, Álvarez RG, Rosales FH, Alonso Y, Schulz S 2009: Preconditioning with ozone/ oxygen mixture induces reversion of some indicators of oxidative stress and prevents organic damage in rats with fecal peritonitis. Inflamm Res 58: 371-375

Schwartz-Tapia A, Martínez-Sánchez G, Sabah F 2015: Madrid Declaration on Ozone Therapy. Madrid. Madrid: ISCO3 (International Scientific Committee of Ozone Therapy), 2015-2020

Sen CK, Khanna S, Babiot BM, Hunt TK, Ellison EC, Roy S 2002: Oxidant-induced vascular endothelial growth factor expression in human keratinocytes and cutaneous wound healing. J Biol Chem 277: 33284-33290

Sen CK, Roy S 2007: Redox signals in wound healing. Biochim Biophys Acta 1780: 1348-1361

Traina AA 2008: Biological effects of ozone in water on dermal wounds healing in rats [Thesis]. São Paulo: Faculty of Dentistry, University of São Paulo

Uysal B, Demirbag S, Poyrazoglu Y, Cayci T, Yesildaglar N, Guven A, Surer I, Korkmaz A 2012: Medical ozone therapy decreases postoperative uterine adhesion formation in rats. Arch Gynecol Obstet 286: 1201-1207

Valacchi G, Bocci V 1999: Studies on the biological effects of ozone: 10. Release of factors from ozonated human platelets. Mediators Inflamm 8: 205-209

Valacchi G, Lim Y, Belmonte G, Miracco C, Zanardi I, Bocci V, Travagli V 2011: Ozonated sesame oil enhances cutaneous wound healing in SKH1 mice. Wound Repair Regen 19: 107-115 
Plate VII

Repciuc C.C. et al.: Management ... pp. 189-194
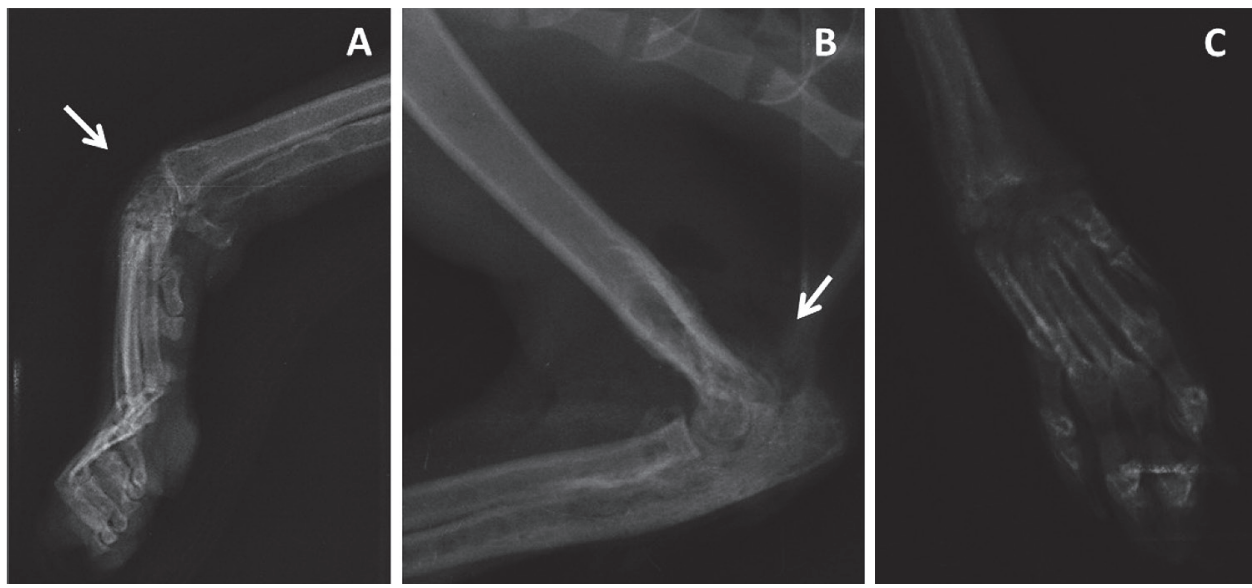

Fig. 1. Radiological aspects of the right forelimb. A. Lateral view of the carpal joint, artrogryposis and degenerescence of the carpal bones and joint; B. Lateral view of the elbow, muscular, subcutaneous abscesses and elbow arthrosis; C. Dorso-palmar view of the carpal joint, arthroticdegenerescence of the carpal joint
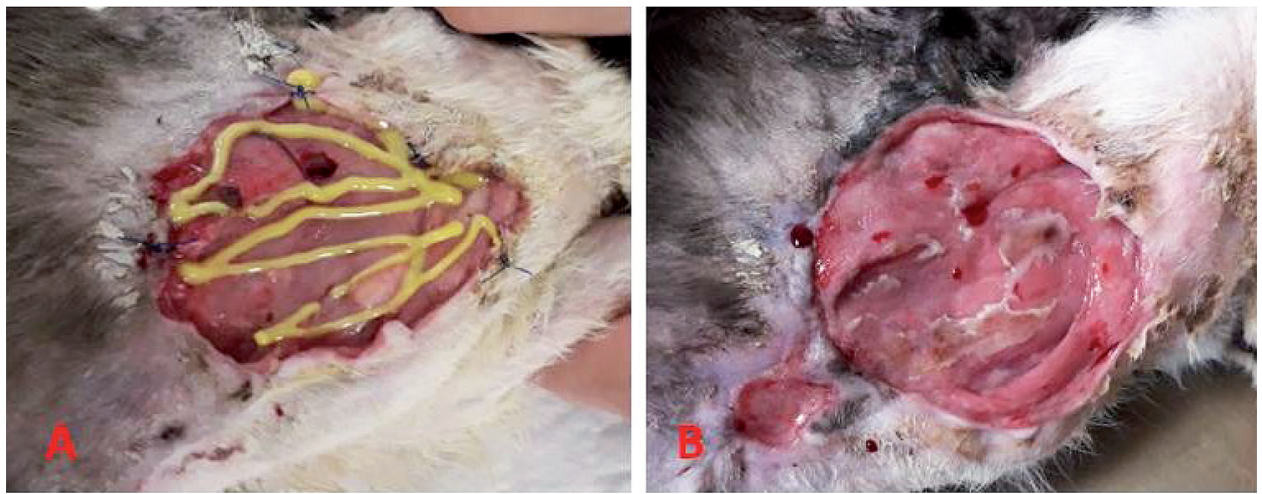

Fig. 2. Wound evolution under classical treatment (A) 5 days after surgery with local treatment on wound (Tenazym) (B) after 14 days of classical treatment and the aspect of the wound at the moment of the first ozone therapy session 

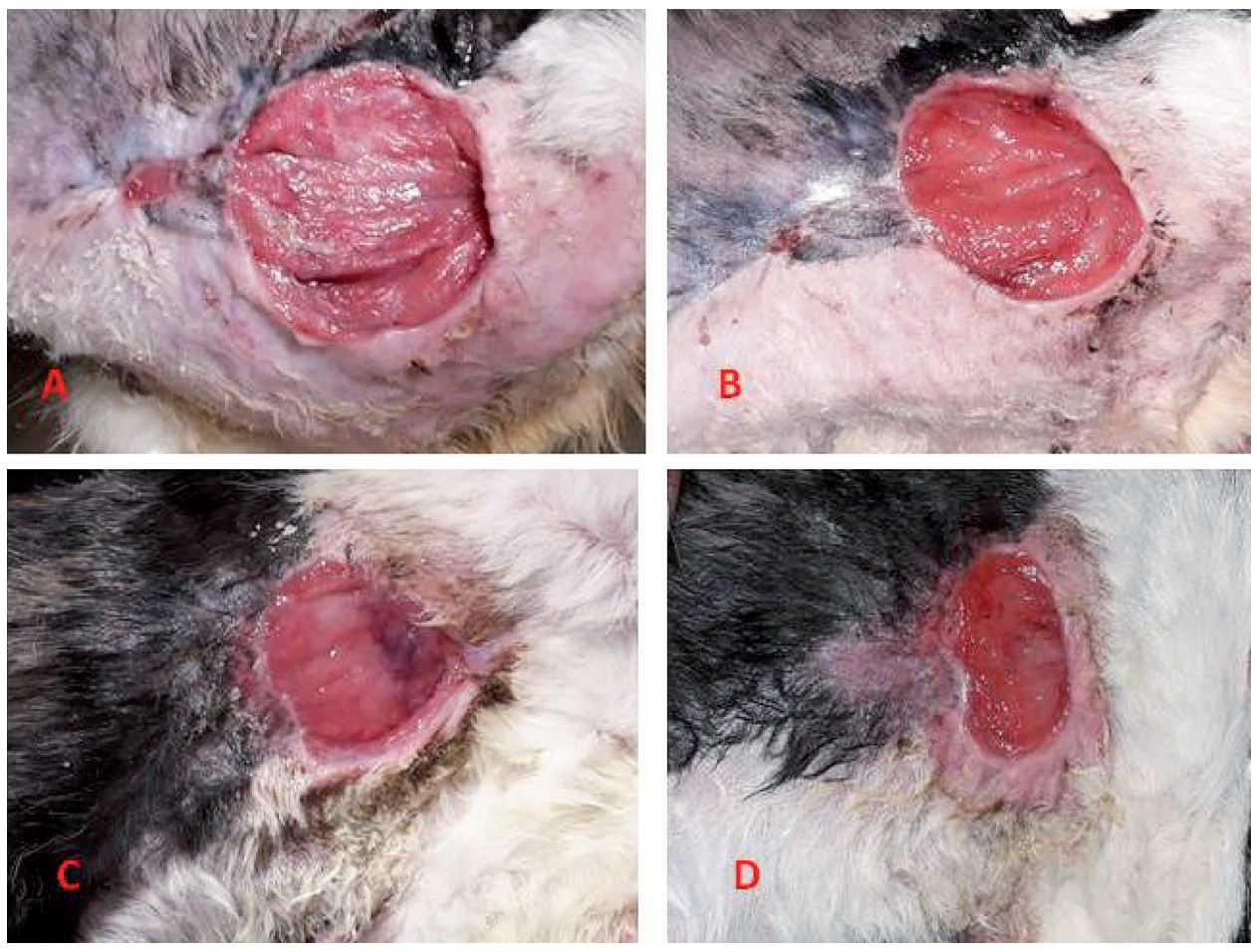

Fig. 3. Wound evolution under ozonetherapy. (A) Second day of treatment $-\mathrm{O}_{3} \times 2$, (B) $6^{\text {th }}$ day of treatment $\mathrm{O}_{3} \times 4,(\mathrm{C}) 28^{\text {th }}$ day of treatment $-\mathrm{O}_{3} \times 15$, (D) $34^{\text {th }}$ day of treatment $-\mathrm{O}_{3} \times 18$ 